\title{
SISTEM PERINGATAN DINI BERBASIS SMS GATEWAY PADA KANTOR IMIGRASI KELAS II PARE-PARE SULAWESI SELATAN
}

\author{
Suryadi Syamsu \\ Program Studi Teknik Informatika, STMIK AKBA \\ Email: adi@akba.ac.id
}

\begin{abstract}
ABSTRAK
Sistem pemberitahuan masa ijin tinggal kepada Warga Negara Asing (WNA) masih menggunakan cara manual karena masih dikerjakan oleh petugas yang terkait dengan cara menghubungi WNA melalui pangilan telepon dan email, sedangkan sistem pada prinsipnya untuk mempermudah pekerjaan dengan cara mengakomodasi sistem yang dilakukan secara manual untuk dikembangkan dalam hal pemberitahuan kepada WNA menggunakan SMS Gateway yang akan mengirimkan pesan peringatan secara otomatis dan terjadwal.Tujuan dari pembuatan sistem peringatan dini berbasis SMS Gateway adalah (1) Mengembangkan sistem peringatan dini berbasis SMS Gateway untuk meningkatkan pelayanan kepada WNA yang berkunjung ke Indonesia.(2)Implementasi sistem peringatan dini berbasis SMS Gateway yang akan Memudahkan pegawai melakukan pemberitahuan kepada WNA pada kantor imigrasi Kelas II Parepare di Sulawesi selatan. Implementasi Sistem Peringatan Dini Menggunakan Tools Gammu, bahasa pemrograman PHP dan database MySQL yang berjalan pada XAMPP Server. Kesimpulan yang didapatkan dari penelitian ini adalah : (1) Kantor Imigrasi Kelas II Parepare Membuat sistem peringatan dini berbasis SMS Gateway untuk membantu proses pemberitahuan ke WNA secara otomatis dan Terjadwal sesuai masa izjin tinggal WNA. (2) Dengan adanya Sistem peringatan dini berbasis SMS Gateway proses pemberitahuan ke WNA yang dulunya manual dan kurang efisien, sekarang menjadi lebih mudah karena semua dilakukan secara otomatis dan terjadwal oleh sistem.
\end{abstract}

Kata Kunci:SMS Gateway, sistem peringatan dini, Gammu, Warga Negara Asing

\begin{abstract}
Foreign residency stay notice system still use manual method because it is still done by officer related to how to contact foreign citizen through phone call and email, while the system in principle to facilitate the work by accommodating the system which is done manually to be developed In the case of notification to foreigners using SMS Gateway which will send an alert message automatically and scheduled. The purpose of designing early warning system based on SMSGateway is: (1) Developing early warning system based on SMS Gateway to improve service to foreigners visiting Indonesia (2) Implementation of SMS Gateway-based early warning system that will facilitate employees to notify foreigners at office Immigration Class II Parepare in south Sulawesi. Implementation Early Warning System Using Gammu Tools, PHP programming languages and MySQL databases running on XAMPP Server. The conclusions drawn from this study are: (1) Class II Parepare Immigration Office Create an SMS Gateway based early warning system to assist the automatic notification process to the Foreigners and Scheduled according to the residence status of foreign citizens. (2) With the SMS Gateway-based early warning system the notification process to WNA that was once manual and less efficient, is now easier because everything is done automatically and scheduled by the system.
\end{abstract}

Keywords:SMS Gateway, Early Warning System, Gammu, Foreign Citizen 


\section{Latar Belakang}

Perkembanganmedia informasi dari waktu ke waktu terus mengalami peningkatan yang sangat pesat. Hal tersebut didukung dengan berkembangnya teknologi yang semakin canggih sehingga informasi dapat diakses secara cepat, tepat dan akurat. Perkembangan teknologi bisa dimanfaatkan oleh Instansi pemerintah maupun swasta untuk mendukung kelancaran proses pekerjaan disetiap bagian masing-masing salah satunya pada kantor imigrasi kelas II parepare di sulawesi selatan.

Kantor Imigrasi Kelas II pareparesebagai bagian dari Kementerian Hukum dan Hak Asasi Manusia Indonesia memiliki tugas pokok merumuskan dan melaksanakan kebijakan dan standarisasi teknis di bidang imigrasi. Kantor Imigrasi Kelas II parepare saat ini telah memiliki sistem informasi yang terintegrasi dengan seluruh wilayah kerja yang ada di Indonesia serta dipermudah dalam hal monitoring WNA (warga Negara Asing) yang ada di Indonesia tetapi dalam implementasi sistem tersebut khususnya masa ijin tinggal WNA hanya memberikan informasi masa berakhir/tenggang surat izin menetap di indonesia kepada petugas terkait untuk selanjutnya petugas tersebut akan menyampaikan kepada WNA yang bersangkutan melalui panggilan telepon ataupun email.

Berdasarkan hal tersebut diatas maka Sistem pemberitahuan masa ijin tinggal kepada WNA masih menggunakan

\section{Tujuan Penelitian}

Tujuan dari perancangan sistem peringatan dini berbasis SMSgatewayadalah sebagai berikut :

1.Mengembangkan sistem peringatan dini berbasis SMS Gateway untuk meningkatkan pelayanan kepada WNA yang berkunjung ke Indonesia.

2. Implementasi sistem peringatan dini berbasis SMS Gateway akanMemudahkan caramanual karena masih dikerjakan oleh petugas yang terkait dengan cara menghubungi WNA melalui pangilan telepon dan email, sedangkan sistem pada prinsipnya untuk mempermudah pekerjaan dengan cara mengakomodasi sistem yang dilakukan secara manual untuk dikembangkan dalam hal pemberitahuan kepada WNA menggunakan SMS Gateway yang akan mengirimkan pesan peringatan secara otomatis dan terjadwal.

SMS Gateway adalah merupakan komunikasi dua arah, mengirim dan menerima, dengan tarif normal yang telah ditentukan oleh operator seluler.(Agus Saputra, 2011).

\section{Rumusan Masalah}

Rumusan masalah dalam penelitian ini yaitu :

1.Bagaimana Pengembangan sistem peringatan dini berbasis SMS Gatewayuntuk mengakomodasi sistem pemberitahuan kepada WNA yang memiliki masa tenggang menetap di Indonesia (izin menetap di Indonesia akan segera habis masa berlakunya) dan dianjurkan untuk segera memperpanjang ataupun segera menyiapkan diri untuk meninggalkan Indonesia.

2. Bagaimana implementasi sistem peringatan dini berbasis SMS Gateway yang berjalan pada web server apache di dalam sistem operasi windows 7 dan terhubung dengan modem GSM

pegawai melakukan pemberitahuan kepada WNA pada kantor imigrasi Kelas II Parepare di Sulawesi selatan

\section{Tinjauan Pustaka}

\section{SMS Gateway}

SMS Gateway adalah merupakan komunikasi dua arah, mengirim dan menerima, dengan tarif normal yang telah 
ditentukan oleh operator seluler.(Agus Saputra, 2011).

\section{Bagan Alur Sistem (Flow Chart)}

Flowchart menggunakan anotasi dan lambang, misalnya segi empat, belah ketupat dan oval, untuk menyatakan berbagai operasi. Garis dan ujung panah menghubungkan lambang-lambang tersebut untuk menunjukkan arah arus data dari satu titik ke titik lain. (Ir. Harianto Kristanto, 2004)

\section{Pemrograman PHP}

PHP adalah singkatan dari "PHP: Hypertext Preprocessor", yang merupakan sebuah bahasa scripting yang terpasang pada HyperText Markup Language (HTML). Sebagian besar sintaks mirip dengan bahasa $\mathrm{C}$, Java dan Perl, ditambah beberapa fungsi PHP yang spesifik. Tujuan utama penggunaan bahasa ini adalah untuk memungkinkan perancang web menulis halaman web dinamik dengan cepat. (Dodit Supriyanto, 2008)

\section{Database MySQL}

SQL (Structure Query Language) adalah suatu bahasa komputer yang mengikuti standar American National Standard Institute (ANSI), yaitu sebuah bahasa standar yang digunakan untuk mengakses dan melakukan manipulasi sistem database (Yakub, 2008).

\section{Gammu}

Gammu merupakan pustaka SMS Gateway Server yang diciptakan oleh Micar Cihar seorang programmer pyton berkebangsaan Jerman. Cihar membangun beberapa library yang tujuannya hanya untuk memanajemen telepon seluler

\section{Modem GSM}

Modem berasal dari singkatan Modulator Demodulator. Modulator merupakan bagian yang mengubah sinyal informasi kedalam sinyal pembawa (carrier) dan siap untuk dikirimkan, sedangkan
Demodulator adalah bagian yang memisahkan sinyal informasi (yang berisi data atau pesan) dari sinyal pembawa yang diterima sehingga informasi tersebut dapat diterima dengan baik. Modem merupakan penggabungan kedua-duanya, artinya modem adalah alat komunikasi dua arah.

\section{Arsitektur Sistem}

Arsitektur Sistem adalah sebuah bagan yang menggambarkan bagaimana sistem peringatan dini berbasis SMS Gatewaybekerja seperti yang digambarkan pada gambar 1 .

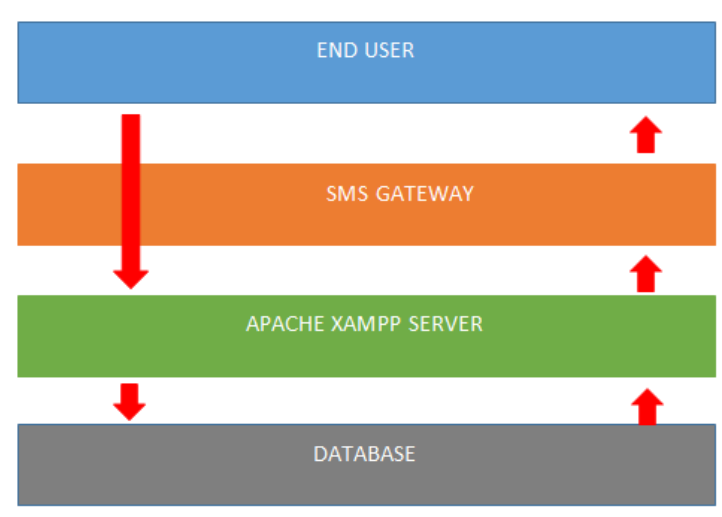

Gambar 1. Arsitektur sistem

\section{Spesifikasi Software}

Sistem peringatan dini berbasis SMS gateway membutuhkan Spesifikasi Software seperti pada tabel 1. agar bisa berfungsi dengan baik.

Tabel 1. Spesifikasi Software

\begin{tabular}{|l|l|l|}
\hline No & \multicolumn{1}{|c|}{ Spesifikasi } & \multicolumn{1}{|c|}{ Versi } \\
\hline 1 & Web server & $\begin{array}{l}\text { Xampp 3.2.2 or } \\
\text { higher }\end{array}$ \\
\hline 2 & $\begin{array}{l}\text { Bahasa } \\
\text { Pemrograman }\end{array}$ & $\begin{array}{l}\text { PHP5or higher } \\
\text { with Curl }\end{array}$ \\
\hline 3 & Database server & Mysqlserver 5.3 \\
\hline 4 & Gammu & 1.33 .0 - windows \\
\hline
\end{tabular}

\section{Spesifikasi Hardware}

Sistem peringatan dini berbasis SMS gateway membutuhkan Spesifikasi hardware seperti pada tabel 2. agar bisa berfungsi dengan baik. 
Tabel 2. Spesifikasi Software

\begin{tabular}{|l|l|l|}
\hline No. & \multicolumn{1}{|c|}{ Spesifikasi } & \multicolumn{1}{|c|}{ Ket. } \\
\hline 1 & $\begin{array}{l}\text { Proc Intel Core i5, } \\
\text { Mem 8 GC DDR3, }\end{array}$ & \\
& $\begin{array}{l}\text { HDD 500 GB, LAN } \\
\text { Ethernet,USB Port }\end{array}$ & \\
\hline 2 & $\begin{array}{l}\text { Modem GSM + Kartu } \\
\text { Seluler }\end{array}$ & SMS \\
\hline
\end{tabular}

\section{Rancangan Sistem Peringatan Dini}

Bagan alur sistem pada sistem peringatan dini berbasis SMS Gateway digambarkan pada gambar 2.

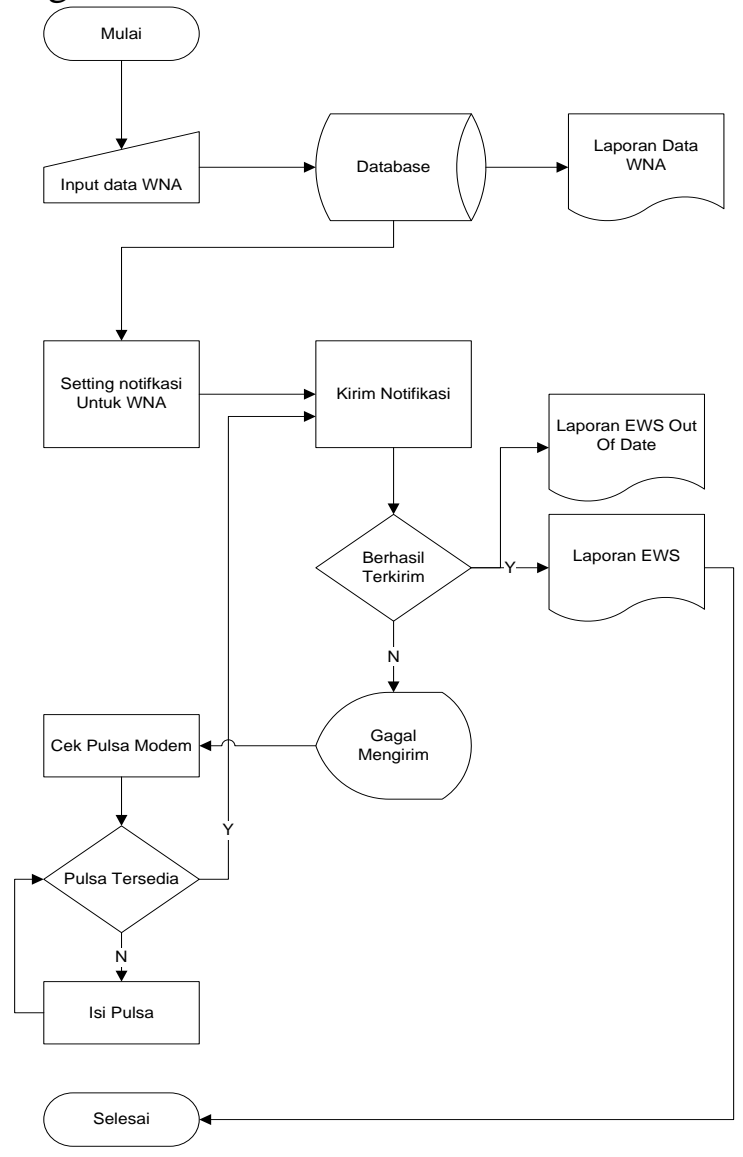

Gambar 2. Bagan Alur Sistem

\section{Desain Interface Sistem Peringatan dini berbasis SMS Gateway}

\section{FormLogin Sistem}

FormLogin berfungsi autentikasi bagi pengguna sistem yang berhak untuk mengakses dengan cara memasukkan username dan password

Imigrasi Pare Pare

(c) Jl. Jendral Sudirman No 87 Pare-Pare

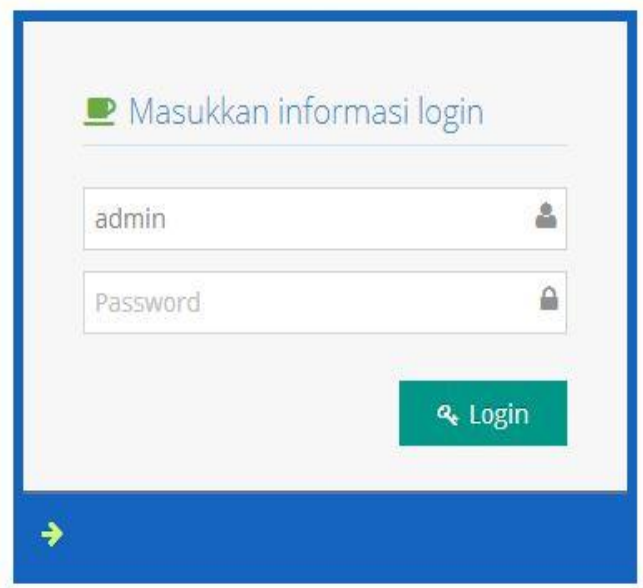

Gambar 3. Form Login

2. Halaman Utama sistem peringatan Dini

Setelah melakukan proses login, apabila berhasil maka akan masuk menu utama dari aplikasi. Untuk Melakukan pemberitahuan kepada WNA secara otomatis,pada menu EWS Sistem kita bisa mengklik tombol Push Notification.

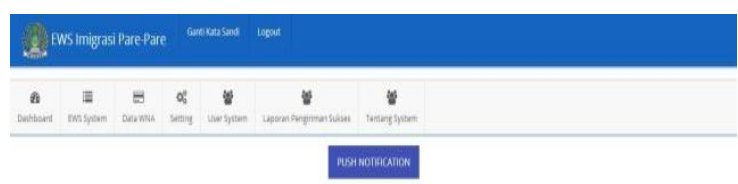

\section{Gambar 4. Halaman Utama EWS}

3. Data WNA

Menu Data WNA berisi informasi data diri WNA termasuk informasi nomor telpon yang akan di hubungi. 


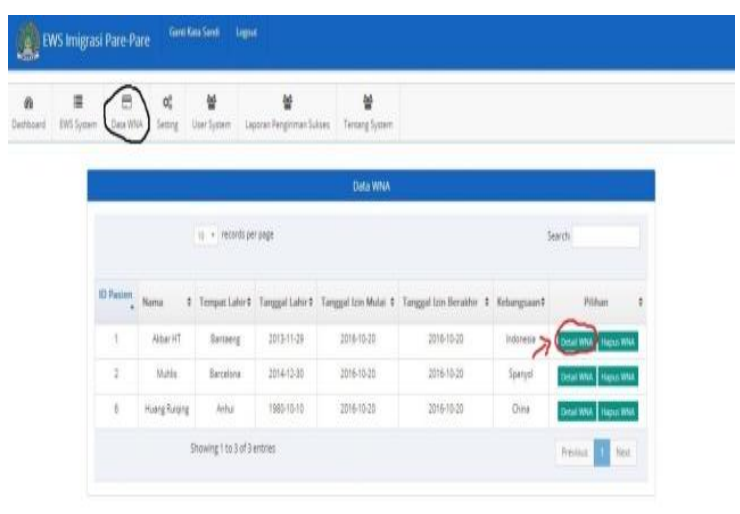

Gambar 5. Data WNA

\section{Edit data WNA}

Form edit data WNA berfungsi untuk mengubah informasi data diri WNA

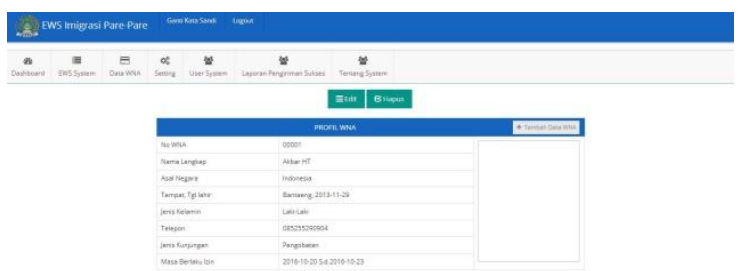

Gambar 6. Edit data WNA

5. Setting Nomor Surat Pemberitahuan

Pada menu setting nomor berfungsi untuk mengatur nomor surat yang akan digunakan untuk pemberitahuan ke WNA

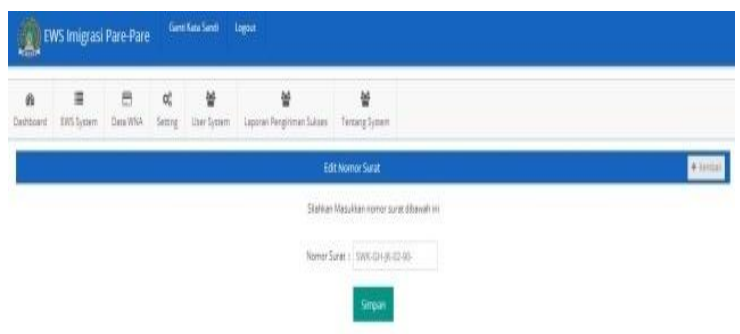

Gambar 7. Setting Nomor Surat

6. Setting Penanggung Jawab Menu penanggung jawab berfungsi untuk mengatur penanggung jawab dalam memberikan notifikasi kepada WNA

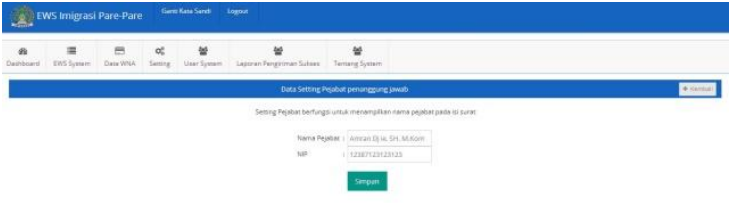

Gambar 8. Setting Penanggung Jawab

7. Setting Konten SMS

Menu setting sms berfungsi untuk memasukkan konten SMS yang akan dikirimkan ke WNA dalam bentuk pemberitahuan via SMS

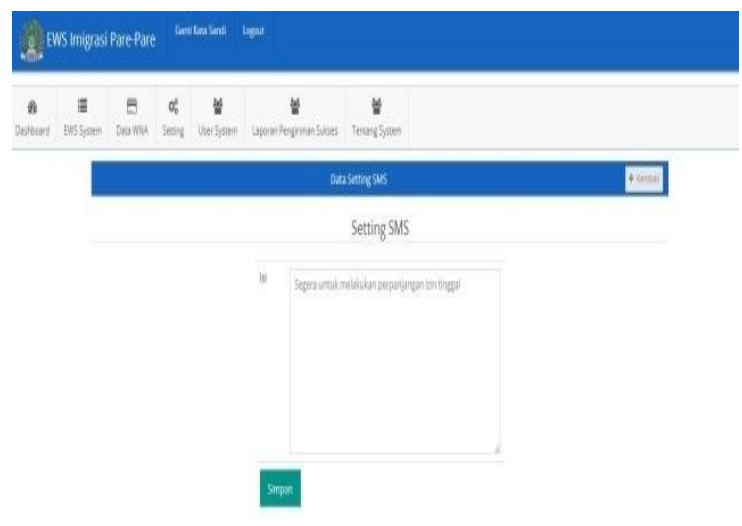

Gambar 9. Setting Konten SMS

8. Setting Waktu Pemberitahuan

Pada menu ini berfungsi untuk mengatur jadwal waktu pemberitahuan kepada WNA.

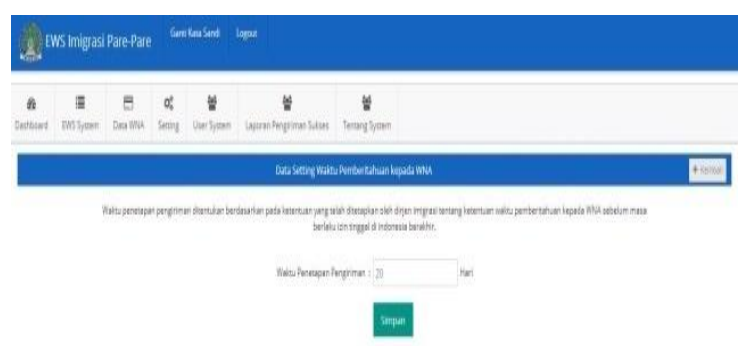

Gambar 10. Setting Waktu Pemberitahuan

9. Laporan Pengiriman

Menu Laporan Pengiriman berfungsi untuk menampilkan informasi pemberitahuan dan masa berakhir izin tinggal WNA. 


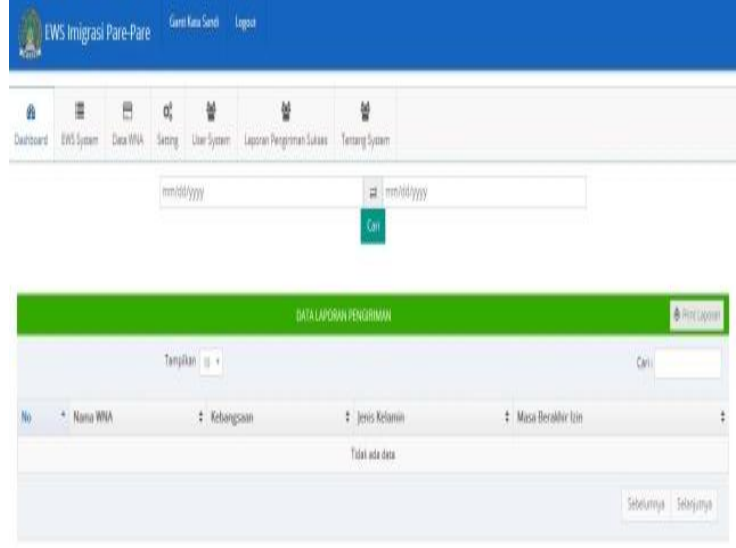

Gambar 11. Laporan Pengiriman

10. Manajemen User

Menu manajemen user berfungsi untuk mengatur hak akses aplikasi serta mengubah username dan password.

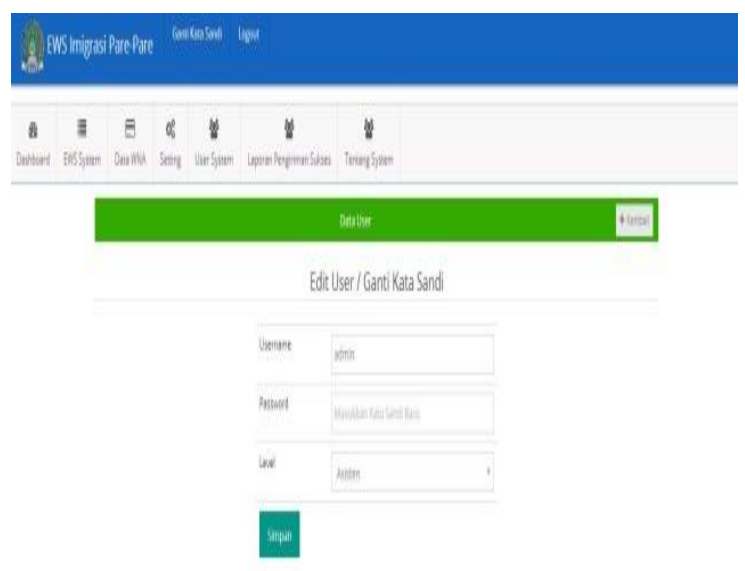

Gambar 12. Manajemen User

\section{Kesimpulan}

1. Kantor Imigrasi Kelas II Parepare Membuat sistem peringatan dini berbasis SMS Gateway untuk membantu proses pemberitahuan ke WNA secara otomatis dan Terjadwal sesuai masa izjin tinggal WNA.

2. Dengan adanya Sistem peringatan dini berbasis SMS Gateway proses pemberitahuan ke WNA yang dulunya manual dan kurang efisien, sekarang menjadi lebih mudah karena semua dilakukan secara otomatis dan terjadwal oleh sistem.

\section{Daftar Pustaka}

[1] Muhammad Taufiq Muslih, Bambang Eka Purnama, Pengembangan Aplikasi Sms Gateway Untuk Informasi Pendaftaran Peserta Didik Baru Di Sman 1 Jepara- IJNS Volume 2 No 1 - Juli 2013 - ISSN: 2302-5700

[2] Saputra, Agus . 2011. Membangun Aplikasi SMS Dengan PHP dan MySQL. Jakarta: Elex Media Komputindo

[3] Dodit Supriyanto, 2008. Buku Pintar Pemrograman PHP. Bandung : Oase Media

[4] Yakub, 2008. Sistem Basis Data; Tutorial Konseptual. Graha Ilmu Yogyakarta.

[5] Harianto Kristanto, Ir. Konsep dan Perancangan Database. C.V ANDI OFFSET: Yogyakarta. 2004.

[6] https://wammu.eu/docs/manual/projec t/index.html\#project 